УДК 311.3

\section{A.A. Bisultanova}

\section{CHARACTERISTIC FEATURES OF RE- FORM OF THE PENSION SYSTEM OF THE RUSSIAN FEDERATION}

It is no secret to anyone that the pension system of the Russian Federation is at the reform stage, therefore, today we can already note the advantages and disadvantages of the reforms, which this study is dedicated to. The author made an attempt to analyze the essence of the reforms, made an excursion into the history of the development of the pension system, emphasized the imperfection of the existing system, those shortcomings that need to be eliminated as soon as possible, as well as those that can be eliminated in a strategic manner. The author emphasizes that one should adopt the foreign experience of reforming the pension system, while not forgetting the uniqueness and specificity of the Russian pension system. The relevance of this topic is that the issues of pension provision of citizens will always concern every citizen in the present and in the future. It is worth mentioning the negative point regarding the pension coverage of citizens who are not officially employed, due to the fact that this category of citizens may be deprived of pension coverage in old age, or when appropriate conditions occur. The author also emphasized that it is in the interest of every citizen to keep abreast of all the reforms and changes occurring in the pension system of the Russian Federation, therefore, it is necessary to use all available opportunities to obtain additional information, whether it be the media or Internet resources.

Keywords: pensions, pension reform, individual pension coefficient.

\section{А.А. Бисултанова' \\ ХАРАКТЕРНЫЕ ЧЕРТЫ РЕФОРМЫ ПЕН- СИОННОЙ СИСТЕМЫ РОССИЙСКОЙ ФЕ- ДЕРАЦИИ}

Ни для кого не секрет, что система пенсионного обеспечения Российской Федерации находится на этапе рефоомирования, следовательно, уже сегодня можно отметить преимущества и недостатки проведённых рефрорм, чему и посвящено данное исследование. Автором сделана попытка проанализировать сущность проведённых реформ, сделан экскурс в историю развития пенсионной системы, подчёркнуты несовершенства существующей системы, те недостатки, которые требуют скорейшего устранения, а также те, которые можно устранить в стратегическом порядке. Автором сделан акцент на том, что следует перенять зарубежный опыт реформирования пенсионной системы, не забывая при этом об уникальности и специфичности российской пенсионной системы. Актуальностью рассматриваемой темы является то, что вопросы пенсионного обеспечения граждан всегда будут касаться каждого гражданина и в настоящем, и в будущем. Стоит сказать и о том негативном моменте, касающемся пенсионного обеспечения граждан, не являющихся официально трудоустроенными, в связи с тем, что данная категория граждан может быть лишена пенсионного обеспечения в старости, либо при наступлении соответствующих условий. Автором также подчёркнуто и то, что в интересах каждого гражданина быть в курсе всех реформ и изменений, происходящих в системе пенсионного обеспечения Российской Федерации, следовательно, необходимо использовать все имеющиеся возможности для получения дополнительной информации, будь то средства массовой информации, либо интернет-ресурсы.

Ключевые слова: пенсии, пенсионная реформа, индивидуальный пенсионный коэфффициент.

DOI: 10.36807/2411-7269-2020-2-21-85-88

\footnotetext{
${ }^{1}$ Бисултанова А.А., доцент кафедры финансов и кредита, кандидат экономических наук, доцент; Федеральное государственное бюджетное образовательное учреждение высшего образования "Чеченский государственный университет", г. Грозный

Bisultanova A.A., Associate Professor of the Department of Finance and Credit, PhD in Economics, Associate Professor; Federal State Budget Educational Institution of Higher Education "Chechen State University", Grozny

E-mail: zhanno44ka@mail.ru
} 
Современная сложная общественно-политическая ситуация, сложившаяся в Российской Федерации, связанная с глобальными мировыми кризисами, внутренними диспропорциями в экономике, обострением социальной напряжённости в обществе, требует ориентации социально-экономической политики государства на повышение уровня и качества жизни населения. Одним из фрондов, отвечающих за социальное обеспечение граждан, является Пенсионный фонд, который оказывает большое влияние на экономику страны, так как основной целью его создания и функционирования является забота о социальном обеспечении человека. Пенсионный фонд Российской Федерации является наиболее значимым объектом в системе социального обеспечения граждан, по своим размерам и объёму выполняемых операций он не имеет аналогов. Несмотря на большое количество территориальных подразделений фонда (свыше 2 тысяч), фоонд характеризуется высоким уровнем централизации. Главными задачами Пенсионного Фонда до 2001 г. являлись сбор страховых взносов и погашение просроченной задолженности, обеспечение своевременной выплаты пенсий. Стоит отметить в данном контексте то, что ещё в 1992 г. в некоторых регионах страны был начат процесс создания единых пенсионных служб, занимающихся назначением и выплатой пенсий. Затем, с принятием Указа Президента РФ от 27 сентября 2000 г. № 1709 "О мерах по совершенствованию управления государственным пенсионным обеспечением в Российской Федерации", органам региональной власти было рекомендовано заключить с Пенсионным фондом РФ соглашения о передаче территориальным органам ПФР полномочий по назначению и выплате пенсий, находящихся на тот момент у органов социальной защиты.

С 1997 г. всё большее место в системе пенсионного обеспечения начинает занимать Информационный центр персонифицированного учёта, созданный для обеспечения оперативного взаимодействия со всеми территориальными отделениями ПФР и для ведения базы данных персонифицированного учёта центрального уровня. Также в 1997 г. были приняты два судьбоносных законопроекта для системы пенсионного обеспечения России:

- $\quad$ Федеральный закон от 15.12.2001 № 167-Ф3 "Об обязательном пенсионном страховании в Российской Федерации";

- $\quad$ Федеральный закон от 17.12.2001 № 173-Ф3 "О трудовых пенсиях в Российской Федерации".

В соответствии с принятыми законами пенсия стала состоять из трёх частей:

1) базовая;

2) страховая;

3) накопительная.

В ходе этой реформы размер пенсионного пособия стал определяться реальным заработком и величиной взносов, а не только выработанным стажем. На накопительную долю дали право не всем пенсионерам, а только тем, кто родился после 1953 г. - мужчины, 1957 г. - женщины. Для этого им требовалось перечислять до 4 \% заработка на эту часть. Также будущие пенсионеры получили возможность перенести означенную часть своего пособия из госкомпании в НПФ или частную управляющую компанию (УК). 2005 г. ознаменовался тем, что в бюджете ПФР образовалась финансовая дыра. Из-за этого накопительная доля была отменена лицам, коим не повезло родиться до 1967 г. Высвобождёнными средствами профинансировалась страховая часть [3].

До 2008 г. правительство больше не предпринимало никаких усилий по увеличению пенсионных накоплений граждан. А в указанное время всем родившимся в 1967 г. и позже накопительную часть повысили с 4 до 6 \%. Как уже было сказано, пенсия формировалась из 3 частей. В 2010 г. правительство убрало базовую часть, оставив страховую и накопительную. В 2012 г. пенсию начали оформлять граждане из числа тех, кто платил взносы в 2 \% с 2002 по 2004 гг. По итогам новой пенсионной рефоомы, которая состоялась в 2013 г., правительство создало 3 уровня обеспечения. К уже известному гражданам страховому и накопительному обеспечению добавилась возможность участия в корпоративной системе страхования.

Согласно статистике, за данный год общий объём пенсионных накоплений по стране превысил суму в 2,5 трлн руб., из которых почти 1 трлн руб. находился под управлением частных и негосударственных компаний. В сентябре того же года прошла новость о том, что в следующем, 2014 г., произойдёт замораживание перечисления средств в накопительную часть, а освободившиеся средства пойдут на увеличение страховой доли. Первоначально правительство планировало такой шаг только в отношении 2014 г. Но состояние экономики было таковым, что его пришлось продолжить и в 2015 и 2016 гг. Речь в 
кулуарах шла даже о полной отмене накопительной части. К счастью, руководство страны на такой шаг не пошло.

Новый закон о пенсионной реформе был принят 27 сентября 2018 г., 3 октября того же года документ был одобрен Советом Федерации и подписан Президентом. Согласно этого закона пенсионный возраст женщины был снижен на 3 года - до 60 лет, также были введены льготные условия по выходу на пенсию - в 2019 и 2020 гг. [1], [4], [5]. При этом примечательно, что:

- 2019-2022 гг. мужчины и женщины смогут выходить на пенсию ежегодно с перерывами по полгода-год;

- $\quad$ после 2022 г. выход на пенсию будет происходить только по чётным годам (2024, 2026 и 2028);

- $\quad$ после 2028 г., когда завершатся переходные положения, выход на пенсию снова будет происходить ежегодно - и в чётные годы, и в нечётные (2029, 2030 г. и т.д.) [6], [7]. (Табл. 1):

По годам рождения соответствующие изменения выглядят следующим образом

Талица 1 - График выхода на пенсию мужчин и женщин по годам

\begin{tabular}{|c|c|c|c|c|}
\hline \multicolumn{2}{|c|}{ Женщины } & \multicolumn{2}{|c|}{ Мужчины } & \multirow{2}{*}{$\begin{array}{c}\text { Год выхода } \\
\text { на пенсию }\end{array}$} \\
\hline Год рождения & $\begin{array}{l}\text { Новый пенси- } \\
\text { онный возраст }\end{array}$ & Год рождения & $\begin{array}{l}\text { Новый пенси- } \\
\text { онный возраст }\end{array}$ & \\
\hline 1964 & 55,5 & 1959 & 60,5 & 2019 и 2020 \\
\hline 1965 & 56,5 & 1960 & 61,5 & 2021 и 2022 \\
\hline 1966 & 58 & 1961 & 63 & 2024 \\
\hline 1967 & 59 & 1962 & 64 & 2026 \\
\hline 1968 и далее & 60 & 1963 и далее & 65 & 2028 и далее \\
\hline
\end{tabular}

Таким образом, переходный период пенсионной реформы продлится в течение 10 лет - с 2019 по 2028 гг. При этом окончательно новый пенсионный возраст для женщин и мужчин будет установлен в течение 5 лет - к 2023 г.

Отличительной особенностью данной пенсионной системы является то, что право на пенсию получают не только, накопив требуемый стаж, но и заработав необходимое количество баллов (сегодня - 13,8, к 2025 г. - не менее 30). А накопленные баллы переводятся в рубли, причём стоимость балла ежегодно индексируется в зависимости от темпов роста инфляции. К стоимости балла прибавляется ффиксированная выплата. Начислением баллов занимаются сотрудники ПФ РФ, на количество накопленных баллов влияет целый ряд факторов, в зависимости от того, какой тип накоплений выбран гражданином - исключительно страховой или комбинированный вариант. Если он выбирает исключительно страховой вид пенсии, то максимальное количество баллов, которое ему может начисляться в 2025 г., составит 10. В 2020 г., пока процесс повышения минимального количества ИПК не завершён, работающему человеку в год может начисляться не более 8,6 балла. При выборе будущим пенсионером комбинированного варианта, сочетающего и страховую, и накопительную пенсию, максимальное количество баллов снижается до 6,25. Это связано с тем, что более четверти выплачиваемых в фонд ПФР взносов шло в накопительную часть. В настоящее время этот вопрос не актуален, в связи с заморозкой данного вида пенсий. Заморожены накопительные отчисления были в 2014 г., и с тех пор этот мораторий ежегодно продлевается. В 2018 г. Президент подписал указ о новом продлении моратория до 2020 г.

Стоит отметить работу "клиентских" служб в процессе назначения пенсий. Они дают реальную возможность значительно сократить сроки назначения пенсий. Особую помощь в данном процессе оказало также внедрение автоматизированной системы контакта со страхователями, ОФК и другими ведомствами, занятыми в процессе реализации пенсионной реформы.

Подводя итоги исследования, следует отметить то значение, какое имеет в свете реализуемой пенсионной реформы уровень самосознания граждан. Люди должны внимательно следить за изменениями, касающимися пенсионного законодательства, так как это, в первую очередь, касается интересов самого гражданина. Необходимо своевременно и точно освещать в средствах массовой информации, в сети Интернет все вводимые изменения и поправки, касающиеся пенсионной реформы. Беспечное отношение к своим 
накоплениям, невнимательная оценка ситуации могут повлечь за собой неблагоприятные последствия, в первую очередь, для потенциального получателя пенсии.

Современная пенсионная система Российской Федерации, всё ещё находится на стадии реформирования, соответственно, есть ещё много недочётов и недостатков, которые требуют более внимательного отношения к себе со стороны властей. В первую очередь, стоит затронуть вопрос непрозрачности расчётов в Пенсионном фонде исчисляемой пенсии, что не может не приносить неудобства потенциальным получателям пенсий. Точная методика расчёта пенсий не является понятной для широкого круга обывателей, что, соответственно, крайне негативно отражается на мнении граждан о проводимой реформе, так как большая часть не понимает суть проводимых реформ и то, положительно или отрицательно они скажутся на размерах будущих пенсий.

Размер пенсионного обеспечения граждан в Российской Федерации остаётся наиболее остро обсуждаемым, поскольку пенсии не возмещают достаточный процент утраченного заработка средне- и высокооплачиваемых работников.

Отметим также и соответствующие риски, о которых не следует забывать при переводе пенсии в накопительную часть. Прежде всего, это риск, связанный с инфляцией и обесцениванием денег, так как для рыночной экономики характерен цикличный характер. Также в условиях кризиса накопления могут быть переоценены за счёт снижения стоимости ценных бумаг. Не стоит также оставлять без внимания риск банкротства негосударственных пенсионных фондов, что является нередким явлением не только для российской экономики, но и для экономик многих зарубежных стран.

Как уже было неоднократно подчёркнуто, современная пенсионная система Российской Федерации находится в процессе реформирования, что даёт надежду на то, что власти смогут найти такие элементы и структуры, которые будут отражать уникальность и специфичность пенсионной системы России, а также удовлетворять всем требованиям граждан в части их достойного пенсионного обеспечения [3]. Следует также воспользоваться мировым опытом пенсионного реформирования [2], [6], в целях недопущения тех ошибок, с которыми столкнулись другие страны, скорейшего перехода к более сбалансированной и социально ориентированной системе пенсионного обеспечения страны.

\section{Список использованных источников}

1. Дудко К.Ю. О возможности повышения пенсионного возраста в РФ // Известия ТулГУ. Экономические и юридические науки. - 2015. - № 4-1.

2. Заболотский Е.Д. Опыт реформирования пенсионных систем стран Европейского союза и возможности его использования в России // Вестник СПбГУ. Серия 5: Экономика. - 2017. - № 3.

3. Иванов С.Ф. Пенсионная реформа-2019: детерминанты, последствия, альтернативы // Демографическое обозрение. - 2019. - № 2.

4. Крутикова В.В. Пенсионные накопления в России: мифы, реальность и альтернативы // Социально-экономические явления и процессы. - 2016. - № 5 // URL: https://cyberleninka.ru/article/n/pensionnye-nakopleniya-v-rossii-mify-realnost-i-alternativy (дата обращения: 25.03.2020).

5. Павлова Т.М. Анализ изменений государственной системы пенсионного обеспечения в России // Молодой учёный. - 2017. - № 49. - C. 194-197 // URL https://moluch.ru/archive/183/46974/ (дата обращения: 25.03.2020).

6. Пудовкин А.В. Мировой опыт использования добровольных и обязательных накопительных пенсионных систем: уроки для России // Вестник МГИМО. - 2016. - № 3.

7. Терентьева И.В. Современный этап реформирования пенсионной системы России: оценка результатов и перспективы // Государственное управление. Электронный вестник. - 2019. - № 72 